\title{
EDITORIAL
}

\section{Amos B Smith, III: chemist, collaborator and mentor}

The Journal of Antibiotics (2016) 69, 189; doi:10.1038/ja.2016.1

$\mathrm{B}$ orn on 26 August 1944 in central Pennsylvania, Amos B Smith, III can often be heard referring to himself as 'just a country boy'. This quip, usually offered with a healthy dose of sarcasm, is typically directed at pseudointellectuals foolish enough to associate being from 'the country' with dimwittedness and ignorance. Although offered in jest, the reality is that Amos Smith is indeed a country boy and embodies all of the superb qualities that one associates with this upbringing. Country boys, like Amos Smith, have a sharp intellect, a keen sense of right and wrong, a passion for life and all that it has to offer, a strong work ethic, a desire to succeed, a fearless wanderlust sort of curiosity, and are exceedingly pragmatic and loyal to family friends and colleagues. As one might expect, these 'Country Boy' qualities have shaped Amos Smith's chemistry career and nearly all can be seen manifest in his published work (700 manuscripts), leadership of Penn's Chemistry Department (Chair, 1988-1996), efforts in our professional community (Founding Editor-in-Chief, ACS Organic Letters, among many other activities), and in the 350 undergraduate, graduate and postdoctoral students whom he has mentored.

With regard to his research career Amos Smith's efforts can be generally defined as synthetic organic; however, in accord with his curious nature and ability to establish meaningful and lasting collaborations, these efforts have evolved in many parallel directions and Smith has led his group to make significant advances in synthetic methods, total synthesis of natural/unnantural products, bioorganic chemistry, organic photochemistry, materials science, and primate chemical communication. Of particular note are Smith's collaborations with the Monell Chemical Senses Center and the late Professors Hirschmann and Hochstrasser, as these efforts produced not only multitudes of significant publications but also fostered an air of collegiality that continues to serve as a source of strength across many departments at Penn. Appropriately, Smith's research has been recognized nationally through several awards from the American Chemical Society (Cope Scholar, Creative Work in Synthetic Organic Chemistry, Guenther, Gassman, and Day Awards and the Nichols Medal) as well as numerous international societies, notably: Japan (Kitasato Institute's Microbial Chemistry Medal, Yamada-Koga Prize, and Order of the Rising Sun Gold Rays with Neck Ribbon) and the Royal Society of Chemistry (Centenary Medal and Lectureship, Simonsen Medal, and Perkin Prize for Organic Chemistry). Within the broader chemistry community Amos Smith's service efforts in the American Chemical Society, both in its governance and as founding Editor-in-Chief of Organic Letters, are unparalleled, in fact rather astonishing given the level of dedication required to maintain his research efforts.

As a former Smith graduate student I have benefited greatly from both the seemingly endless support that Amos Smith provides to all of his students and the 'country boy' qualities that, by example, he instills. It has been a pleasure to help organize this special issue of The Journal of Antibiotics and dedicate it to Amos B Smith, III. Although this issue represents only a subset of individuals whose careers have been positively impacted through collaborations with Amos Smith, I know there are many many more who consider their experience a privilege.

John L Wood

Department of Chemistry and Biochemistry, Baylor University, Waco, TX, USA E-mail: John_L_Wood@baylor.edu 